\title{
Moxifloxacin Hydrochloride
}

National Cancer Institute

\section{Source}

National Cancer Institute. Moxifloxacin Hydrochloride. NCI Thesaurus. Code C38696.

The hydrochloride salt of a fluoroquinolone antibacterial antibiotic. Moxifloxacin binds to and inhibits the bacterial enzymes DNA gyrase (topoisomerase II) and topoisomerase IV, resulting in inhibition of DNA replication and repair and cell death in sensitive bacterial species. 